\title{
AN INVESTIGATION OF CHILDREN'S ATTITUDES TOWARDS PHYSICALLY DISABLED PEERS*
}

\author{
Cindy S. Spillers \\ Wichita State University
}

Mid-American Review of Sociology, 1982, Vol. VII, No. 1:55-69

\section{INTRODUCTION}

With the concept of mainstreaming of handicapped children being at the forefront of special education, and the stipulations imposed by P.L. 94-142 regarding public school education for all handicapped children, normal children are more in contact with children demonstrating disabilities than they previously have been. The school is a major institution affecting a child's socialization. A major aspect of the socialization process is the development of attitudes towards other people. It seems appropriate, then, to investigate the attitudes that physically able-bodied children have towards their physically disabled peers, and at what age these attitudes emerge.

\section{REVIEW OF THE LITERATURE}

Sociological Perspectives: Role Theory and Stigma

In discussing attitudes towards the physically disabled, it is necessary first to address the question of what is a disability and why are people with disabilities considered to be handicapped or treated differently by those with no physical disabilities. The World Health Organization has provided the following definitions:

*The author wishes to thank Ms. Nancy Brooks, M.A., for her advising, and the parents, teachers, and administrators of Nelson Elementary, Haysville, Kansas and Central Preschool, Wichita, Kansas. 
Impairment-a deviation from normal, resulting in poor functioning or development

Disability - a limitation experienced because of an impairment

Handicap - a disadvantage imposed because of an impairment or disability.

From these definitions, it becomes evident that disabilities and handicaps are consequences of the social environment. A disability involves an inhibition in carrying out the normal social roles because of the impairment present. A handicap takes this limitation one step further in that limitations are imposed upon the individual by external consequences. Freidson (1965) postulates that a person is considered handicapped because he deviates from what he or others believe to be normal or appropriate. Organizations designed to assist the handicapped may continue that deviance by separating the disabled individuals from others, and isolating them as a group. Their identity with the organization is based solely on their disability. An example of this can be seen in the special education classrooms of many elementary schools. These classes serve children with various types of physical impairments, mental impairments, and behavioral disorders. Often, the children function at all different levels, academically, yet they have been grouped in the same classroom because they all share some type of disabling characteristics.

Disabilities have long been noted as social attributes that carry either positive or negative connotations. The connotations can be seen in light of the "imputation of deviance" phenomenon. This refers to the notion that the presence of a disability leads to the expectation that the possessor will be different and objectionable. Difference and objectionableness are two key ingredients of deviance, hence, a person with a disability is considered deviant by the non-disabled population. Bartel and Guskin (1971) comment that society creates deviance by selecting certain attributes or norms and regarding them as desirable. Those who fail to conform to these attributes are labeled deviant.

Because people with physical disabilities are often viewed as being different or deviant, they are expected to act differently.
The behaviors which they are expected to display characterize the Sick Role. According to Haber and Smith (1971), the general tendency of the able-bodied population is to treat a disability as an extension of the sick role. In Freidson's discussion of Talcott Parsons' theory of the sick role (1965), he states that, through the sick role, a person considered deviant finds "legitimacy" in his deviance. Legitimation is the process of exempting a person from responsibilities and usual role requirements by explaining the behavioral variations in normatively acceptable terms. The right to behave deviantly-or differently-is conditionally granted, rather than punished. As such, illness becomes an acceptable reason for failing to meet the usual social role obligations (Haber and Smith, 1971). In this way, legitimation can be beneficial to the individual.

Haber and Smith view legitimation as a labeling process. That is, it reinforces the awareness of the individual's limitations through exemption from usual role behaviors, and essentially, licenses the individual to behave according to the incapacities. Labeling has the effect of increasing the visibility of the impairment and emphasizing alternate behaviors that are considered appropriate to the situation.

In addition to exempting one from former role behaviors, legitimation can also stipulate other role requirements, specifically in regard to the Sick Role. The person's sick role is legitimated as long as conformity to the expectations implied in the role are demonstrated. One of these implied expectations is the desire to recover, i.e., the individual must demonstrate that s/he wants to get well and that all that can possibly be done is being done to improve the individual's current health status.

Both Freidson and Haber and Smith suggest that the use of the sick role is limited when applied to the physically disabled population. The major limitation is that the exemption associated with the sick role behaviors is temporary, depending on the duration of the illness. However, most people with physical disabilities will experience the effects for the remainder of their lives. Thus, the desire to get well is often an inappropriate expectation.

Those with disabilities can adapt their functioning but they may never return to their previous "well" state. Because of this, 


\section{Mid-American Review of Sociology}

the sick role addresses how improvement will occur, but does not deal with persistence of the role itself. Although the individual may improve and adapt, total functioning may never be regained, and hence, the individual will not be able to carry out the usual social role according to societal prescriptions. Total acceptance by others, then, remains conditional on pressing them past their usual point of acceptance. Because the individual must meet the social role in a different way, s/he remains further separated or stigmatized, i.e., not totally accepted.

Attitudes: Development and Assessment

The imputation of deviance, stigma, and role casting of the disabled individual, are societal expressions of attitudes. Attitudes are defined as positive or negative reactions to an object. These reactions can be emotional or behavioral in nature, and actually reflect values of a group or individual. Values are such things as acts, customs, and institutions, regarded in a particular way by a group of people. Entities such as these are usually regarded in favorable way, meaning that they are desirable to have or with which to be associated. Attitudes are learned, usually from significant people in our environments. Since they are learned, they can also be changed.

Studies investigating the attitudes of able-bodied people towards those with physical disabilities have largely concluded that the general population holds negative attitudes towards disabled individuals. According to the findings of Harold Yuker (1977), society responds hierarchically to physical disabilities. Those that are the least disfiguring are more easily accepted by social groups than those which are more disfiguring.

Information on how we develop attitudes in general, and those towards the disabled in particular, is speculative. Goodman et al. (1963), posit that individuals develop attitudes towards others through early socialization processes, and that these attitudes reflect cultural values. The authors cite Kluckhon who defined values as implicit or explicit conceptions of something desirable. Goodman et al., state that the value formation involves choice behavior in that the individual chooses what is desirable to him/her-self, and choses whether or not to accept a social group's chosen values.
Attitudes Towards Physically Disabled Peers

The authors further comment that values regarding people with disabilities are implicit. Children are not taught directly that a child with a disability is more or less likable than a child with no disability-or even a child with another type of disability. Few children have direct contact with people having disabilities, hence limiting their opportunities for forming values from firsthand experience. Because of the lack of direct experience, attitudes towards disabled individuals may develop vicariously and indirectly.

Two factors seem to have a significant bearing on the acquisition of cultural values (Goodman et al., 1963): the child's exposure to the value, and his/her ability to learn the value. The absence of either or both of these factors can inhibit value acquisition. It is through adult models (parents, teachers, etc.) that children learn these implicit values and gain exposure to them. In their study, Goodman et al., in fact, found that 10-11 year old children demonstrated having values similar to adults, indicating that, at this age, a good deal of the socialization process regarding attitudes had taken effect. The authors tested their notions by having the 10-11 year old subjects rank order drawings depicting various disabilities. The children's rankings were then compared to the rank orderings of adult subjects. The normative group of children responded in a way that matched the adult group's responses. The other groups of children (Jewish, Italian, Institutionalized psychiatric, Institutionalized and non-institutionalized mentally retarded), however, did not mirror the adult group. These findings lend credence to the notion that exposure to a value is critical in its development in children, as is the notion of ability to learn the value. The various subject groups may not have been exposed to the same values as the normative group, or were not able to learn them, and therefore, did not express attitudes in line with the adult group.

Bartel and Guskin (1971) offer some interesting views regarding the attitudes of children, children considered deviant, and the need to observe and alter our thinking towards the disabled. These authors suggest that the field of special education exists because our society chooses to treat children with distinctive physical and behavioral characteristics differently, because 
others define them as creating a problem, and because social agencies-such as schools-choose to create special arrangements for dealing with them. Children are often socially categorized in schools. They are grouped on the bases of characteristics that have little bearing on their academic achievement, such as the presence of cerebral palsy or bilateral hemiplegia.

Bartel and Guskin pose two potential reasons why some traits or characteristics are chosen over others to differentiate groups of people. First, is the self-connection gradient, which refers to the degree to which traits are viewed as relating to the central core of the individual. These traits can be distinguished by the verbs "to be" and "to have." "To be" traits are more central or core than "to have" traits, and therefore, are more likely to be used for classification purposes. Second, the authors refer to the status value gradient, i.e., the degree to which certain attributes are valued or prized by a social group. Traits contradicting abilities that are highly valued by a social group are singled out as foundations for classification.

Asher, Gottman, and Oden's investigation (1977) can be viewed in terms of how children apply the self-connection gradient and the status-value gradient when choosing friends. Names, physical appearance, race, and sex have been identified as important determiners of peer acceptance. These can also be thought of as "to be" traits. They cite many authors (Dion and Berschield, 1974; Asher, 1975; and Richardson et al., 1961) as having determined that children demonstrate negative attitudes towards others exhibiting "to be" traits which do not conform to their internalized status-value gradients. This includes children with physical disabilities of varying natures and amount of severity, presence or absence of attractiveness, and of a different racial or ethnic background than themselves.

\section{Summary}

A review of the literature reveals that adults and older children exhibit attitudes not favoring physically disabled individuals. These attitudes, in turn, reflect value systems that stigmatize the handicapped as being different and objectionable. The objectionableness of the physically disabled is reinforced by agencies and institutions designed to deal with the handicapped. These agencies capitalize the associated stigma of the individuals by separating them from the remainder of the population, and collecting the "deviates" together, solely on the bases of their difference. The continued stigmatization of the disabled individuals breeds values that decree the physically disabled to be different, which perpetuates negative attitudes. The interaction of attitudes, values, and stigmatization is quite circular.

\section{STATEMENT OF THE PROBLEM}

Literature focusing on the attitudes of adults towards disabled adults is vast (e.g., Doob, 1950; Thomas, 1966; Haber and Smith, 1971; and Smits, 1979). By using adult and adolescent subjects, investigators have the advantage of employing questionnaires such as the "Attitude Toward Disabled Persons Scale" (ATDP), developed by Yuker, Campbell, and Block (1960). With young children, however, it is not always possible to use survey type instruments, primarily because of the limited cognitive capacities of the children in understanding the concepts expressed on these instruments. Researchers tapping children's attitudes have had to utilize such designs as rank ordering of pictures from most to least preferred (Goodman et al., 1963; Richardson, 1971) or showing pictures to children and asking them a set of questions designed to tap various aspects of attitudes (Weinberg, 1979). The former design can be criticized for its potential inutility with children under the age of six years. The primary argument being that such young children may not fully understand the rank ordering task. The latter design lacks reliability and validity in that the questions utilized are usually developed by the individual investigators, with little or no continuity across studies, and no measures of construct validity available.

Studies investigating racial attitudes have tended to use simpler paradigms in which subjects are shown pairs of pictures and asked which child they prefer (e.g., Lerner and Buehrig, 1975). The simplicity of the task in regard to the dichotic nature of the subjects' responses has two advantages: it facilitates data collection, and it can be performed by preschool aged children. 
One major obstacle exists with this design, however. Although the forced paradigm gives a clear indication of a child's preference for potential playmates, one must be cautious in concluding that the child rejects the stimulus picture not chosen in the forced choice paradigm. Lack of preference does not imply rejection, however, few researchers appear to have noted this distinction.

The current study attempted to investigate the attitudes of two different age groups of children towards physically disabled peers along two dimensions: preference and acceptance. A forced choice design, requiring subjects to choose between two pictures, was utilized to measure preference. To measure acceptance, single picture presentations were used. The following hypotheses were tested:

$\mathrm{H}_{1}$ : Third graders and Preschoolers will demonstrate a difference in their preference for either handicapped or able-bodied children in the photographs.

$\mathrm{H}_{2}$ : Third graders and Preschoolers will demonstrate a difference in their acceptance of handicapped or ablebodied children in photographs.

$\mathrm{H}_{3}$ : The third graders will demonstrate a difference in their preference vs. acceptance of handicapped and ablebodied children in photographs.

$\mathrm{H}_{4}$ : The Preschoolers will demonstrate a difference in their preference vs. acceptance of handicapped and able-bodied children in photographs.

\section{METHODS}

Subjects

Thirty-two preschool and 32 third grade children were chosen from the greater Wichita area, to serve as subjects. Eligibility for participation required: (1) normal or corrected vision; (2) an ability to make a preferential choice between neutral pairs of pictures; (3) an ability to make a yes-no response to questions of acceptance regarding neutral pictures.

\section{Stimuli}

Individual photographs of eight children ( 4 boys and 4 girls) were taken using a Polaroid Pronto camera. Two pictures of each child were required: one of the child sitting in a wheelchair, and one of the child standing upright. This yielded a total of 16 photographs. The children for the stimuli were chosen so that there would be two preschool boys, two preschool girls, two third grade boys, and two third grade girls. In addition to these stimuli, some neutral pictures depicting pets, foods, and toys were used as practice items.

\section{Procedures}

For the forced choice condition, the photographs of the children were paired so that the "disability" picture was matched with an "able-bodied" picture of the same age and sex. For example, the picture of one preschool boy in the wheelchair was paired with the picture of the other preschool boy standing. This yielded two complimentary sets of four pairs of photographs. The pairs were then counterbalanced for age, sex, and order of presentation. One set of photographs was presented to each subject, one pair at a time. Subjects were asked: "Which child would you like to play with?"

For the acceptance condition, one photograph from each pair was shown to the subjects. Again, the stimuli were counterbalanced. Only one photograph from each of the four pairs which the subject saw in the preference condition was used in the acceptance condition. Subjects were asked: "Would you like to play with this child?"

Subjects were tested individually, in a room separate from their regular classroom. The order of testing was altered so that some children received the preference measure first, whereas others received the acceptance measure first. Each subject saw only half of the eight complimentary pairs, or four pairs of photographs. The entire procedure required 5-10 minutes per subject. 


\section{RESULTS}

The data were analyzed using a Chi square. All but one $\mathrm{X}^{2}$ values proved significant beyond the .05 or .01 level of confidence (see Table 1).

Table 1

\begin{tabular}{|c|c|c|c|}
\hline & & Value & Signif. \\
\hline $\mathrm{x}^{2}{ }_{1}$ & $\begin{array}{l}\text { Preference for Handicapped vs. Able-bodied } \\
\text { between 3rd graders and preschoolers }\end{array}$ & 16.25 & .01 \\
\hline $\mathrm{x}^{2}{ }_{2}$ & $\begin{array}{l}\text { Acceptance of Handicapped vs. Able-bodied } \\
\text { between 3rd graders and preschoolers }\end{array}$ & 1.44 & NS \\
\hline $\mathrm{x}^{2}{ }_{3}$ & $\begin{array}{l}\text { Preference of Handicapped vs. Able-bodied } \\
\text { for 3rd graders only }\end{array}$ & 6.125 & .05 \\
\hline$x^{2}{ }_{4}$ & $\begin{array}{l}\text { Acceptance of Handicapped vs. Able-bodied } \\
\text { for 3rd graders only }\end{array}$ & 72.12 & .01 \\
\hline$x^{2}{ }_{5}$ & $\begin{array}{l}\text { Preference of Handicapped vs. Able-bodied } \\
\text { for preschoolers only }\end{array}$ & 84.25 & .01 \\
\hline $\mathrm{x}_{6}^{2}$ & $\begin{array}{l}\text { Acceptance of Handicapped vs. Able-bodied } \\
\text { for preschoolers only }\end{array}$ & 30.186 & .01 \\
\hline
\end{tabular}

Chi square 1 demonstrates that Preschoolers and 3 rd graders differ in their preference of handicapped vs. able-bodied pictures, with preschoolers preferring the able-bodied children and 3rd graders preferring the handicapped children. These findings support the claim that the two age groups will differ in their preference, however, the difference occurred in the opposite direction than was expected. Chi square 2 indicates that both groups accepted the handicapped children about the same, and both accepted the handicapped pictures significantly more than they rejected them.

Chi squares 3 and 4 indicate that the 3 rd graders preferred the pictures of the handicapped children over the able-bodied children with significantly greater frequency, and that they accepted the handicapped and able-bodied pictures more than they rejected them. Chi squares 5 and 6 indicate that the preschoolers preferred the able-bodied pictures over the handicapped pictures with significantly greater frequency and that they, too, accepted both more than they rejected them. It seems, then, that both preschoolers and 3rd graders showed high acceptance of the handicapped pictures, regardless of their preferences. This supports the claim that preference and acceptance are not related.

\section{DISCUSSION}

The results of the current study appear to be in opposition to the results of previous works (e.g., Goodman, 1963; Weinberg, 1979) which have demonstrated that older children prefer ablebodied children over handicapped children, and that younger children do not demonstrate a clear preference. The use of a dichotomous task, such as was employed in this study, allows an experimenter to measure the decisions made by the subjects without the benefit of insight into the child's decision-making process. Hence, it was necessary to rely on experimenter observation to help interpret these statistical results.

Many of the 3rd grade children demonstrated some deliberation in choosing between the able-bodied and disabled pictures or accepting or rejecting the disabled pictures. Several children made comments to the effect that they would choose to play with the child in the wheelchair because s/he probably had fewer friends than the able-bodied child, that they had never played with anyone in a wheelchair before, or that "there's nothing wrong with a wheelchair." Other children hesitated in accepting and/or rejecting the handicapped picture, expressing comments such as "I guess it would be okay to play with her;" or "I really wouldn't want to play with him because he couldn't do the things I like to do."

The comments of the 3rd grade children paired with their hesitations may evidence the notion that they were making socially preferred responses. Elkin (1968) views socialization in terms of impression management. Over a period of time, children learn what kinds of behaviors leave what kinds of impressions on people. Elkin further holds that the "self" is something about which we want to create impressions. In order to manage the impressions of others, we need to develop a self, be able to take another's position, and view our own behavior objectively. 
The statements of the 3rd graders, such as "That (handicapped) child probably doesn't have many friends," indicate that some of them were able to view things from the handicapped child's perspective and to see how their own choice behavior might affect that child.

Elkin also refers to the notion of the "generalized other," which is a set of standards and views which a child uses to judge his/her own behavior, and that of others. The generalized other is most likely learned through instruction and is internalized by the child. It can be said to contain all of the social prescriptions and conformities ascribed to by the child, as well as by the parents and teachers of that child.

It is believed that the cognitive capacities of children do not allow for role taking and social maturity until the approximate age of 7 years (Hersh et al., 1979). Conceivably, then, the preschoolers were not at a level of cognitive nor social development to be able to demonstrate the prescriptions of the generalized other, as did the 3rd graders. As a group, then, the 3rd grade subjects may have been responding according to the codes of the generalized other that mandate an altruistic acceptance of everybody, by preferring the handicapped child.

In line with Elkin's notion of the generalized other, it is logical to presume that this set of standards is carried with the child into adulthood. This can help to explain why, as adults, we sometimes do things that are socially preferred or expected, even though those behaviors may not be what we honestly want to do. The social conscience of adults is very strong. It appears from these results that the 3 rd graders were demonstrating a similar tendency towards social prescription, and the development of a strong social conscience.

\section{CONCLUSION}

The above discussion is based upon the premise that the 3rd grade subjects were demonstrating social desirability as a potential motive for their decisions. To further test this notion, and to test the strength of the generalized other, additional studies are needed. Many studies investigating racial attitudes have utilized measures of latency of response, or social distance (Verna, 1981) under the assumption that allowing the child more response freedom than is accorded by forced-choice designs, provides a more valid attitude measure. It is suggested, then, that studies of this type also be conducted in regard to children's attitudes towards disabled peers. Second, it is suggested that studies investigating the learning of social desirability be conducted in an effort to determine who are the agents of social desirability for attitudes towards the disabled.

\section{REFERENCES}

Asher, S.R., Gottman, J.M., and Oden, S.L.

1977 "Children's Friendship in School Settings," in Hetherington E.M. and Parke, R.D. (eds.), Contemporary Readings in Child Psychology. New York: McGraw-Hill.

Bartel, N.R. and Guskin, S.L.

1971 "A Handicap as a Social Phenomenon," in Cruickshank, W.M. (ed.), Psychology of Exceptional Children and Youth. New York: Prentice-Hall.

Billings, H.K.

1963 "An Exploratory Study of the Attitudes of Noncrippled Children Towards Crippled Children," Journal of Experimental Education 31:381-387.

Centers, L. and Centers, R.

1963 "Peergroup Attitudes Towards the Amputee Child," Journal of Social Psychology 61:127-132.

Donaldson, J. and Martinson, M.C.

1977 "Modifying Attitudes Towards Physically Disabled Persons," Doob, L.W. Exceptional Children 43(6):337-344.

1950 "Attitudes and the Availability of Knowledge Concerning Traditional Beliefs," Journal of Abnormal and Social Psychology 59(2):86-90.

Elkin, F.

1968 "Socialization and the Presentation of Self," pp. 374-382 in Heiss, J. (ed.), Family Roles and Interaction: An Anthology. New York: Rand McNally.

Freidson, E.

1966 "Disability as Social Deviance," in Sussman, M.B. (ed.), Sociology and Rehabilitation. Washington, D.C.: American Sociological Association. 
Goodman, N., Dornbusch, S.M., and Hastorf, A.H.

1963 "Variant Reactions to Physical Disability," American Sociological Review 28:429-435.

Haber, L.D. and Smith, R.T.

1971 "Disability and Deviance: Normative Adaptations of Role Behavior," American Sociological Review 36:87-97.

Hartup, W.T.

1970 "Peer Interaction and Socialization," in Mussen, P.E. (ed.), Carmichael's Manual for Child Psychology, Vol. 2 (3rd ed.). New York: John Wiley and Sons.

Hersh, R.H., Paolitto, D.P., and Reemer, J.

1979 Promoting Moral Growth: from Piaget to Kohlberg. New York: Logman, Inc.

Jones, R.L. and Sisk, D.A

1967 "Early Perceptions of Orthopedic Disability," Exceptional Children 34:42-43.

Lazar, A.L., Gensley, J., and Orpet, R.E.

1971 "Changing Attitudes of Young Mentally Gifted Children Towards Handicapped Persons," Exceptional Children 37(8):600602.

Lerner, R.M. and Buehrig, C.J.

1975 "The Development of Racial Attitudes in Young Black and White Children," Journal of Genetic Psychology 127:45-54.

Rapier, J., Adelson, R., Carey, R., and Croke, K.

1972 "Changes in Children's Attitudes Towards the Physically Handicapped," Exceptional Children 39(3):219-223.

Richardson et al.

1961 "Cultural Uniformity in Reaction to Physical Disability," American Sociological Review 26:241-247.

Rollins, B.C. and Thomas, D.L.

1979 "Parental Support Power, and Control Techniques in the Socialization of Children," in Burr; Hill, Nye, and Reiss (eds.), Contemporary Theories About the Family, Vol. 1. New York: Free Press.

Smits, S.J.

1979 "Reactions of Self and Others to the Obviousness and Severity of Physical Disability," pp. 56-60 in Bolten, B. and Jaques, M.E. (eds.), The Rehabilitation Client. Baltimore, Md.: University Park Press.

Thomas, E.J.

1966 "Problems of Disability From the Perspective of Role Theory," Turner, R.H.

ournal of Health and Human Behavior 7:2-14.

1970 Family Interaction. New York: John Wiley and Sons.
Verna, G.B.

1981 "Use of a Free-Response Task to Measure Children's Race PrefWeinberg, N. erences," Journal of Genetic Psychology 138:87-93.

1979 "Preschool Children's Perceptions of Orthopedic Disability," pp. 49-55 in Bolten, B. and Jaques, M.E. (eds.), The Rehabilitation Client. Baltimore, Md.: University Park Press.

Westervelt, V.D. and McKinney, J.D.

1980 "Effects of a Film on Nonhandicapped Children's Attitudes Toward Handicapped Children," Exceptional Children 46(4): 294-295.

Yarrow, M.R.

1960 "The Measurement of Children's Attitudes and Values," in Mussen, P.H. (ed.), Handbook of Research Methods in Child Development. New York: John Wiley and Sons.

Yuker, H.E.

1977 "Attitude of the General Public Toward Handicapped Individuals." Awareness Papers Washington, D.C.; White House Conference on Handicapped Individuals.

Yuker, H.E., Block, J.R., and Younng, J.H.

1966 "The Measurement of Attitudes Towards Disabled Persons." Albertson, N.Y.: Human Resources Center (Human Resources Study No. 7)

Yuker, H.E., Campbell, W.J. and Block, J.R.

1960 "A scale to Measure Attitudes Toward Disabled Persons." Albertson, N.Y.: Human Resources Center. 